\title{
A monstrificação dos irlandeses na imaginação geográfica de Giraldus Cambrensis
}

Turning the Irish into monsters. The geographical imagination of Giraldus Cambrensis

Raimundo Sousa

\section{(2) OpenEdition}

\section{Journals}

\section{Edição electrónica}

URL: http://journals.openedition.org/medievalista/1259

DOI: $10.4000 /$ medievalista.1259

ISSN: $1646-740 X$

\section{Editora}

Instituto de Estudos Medievais - FCSH-UNL

\section{Refêrencia eletrónica}

Raimundo Sousa, «A monstrificação dos irlandeses na imaginação geográfıca de Giraldus

Cambrensis ", Medievalista [Online], 21 | 2017, posto online no dia 01 junho 2017, consultado no dia 03 maio 2019. URL : http://journals.openedition.org/medievalista/1259; DOI : 10.4000/ medievalista.1259

\section{(C) IEM}


Título / Title: A monstrificação dos irlandeses na imaginação geográfica de Giraldus Cambrensis / Turning the Irish into monsters. The geographical imagination of Giraldus Cambrensis

Autor(es) / Author(s): Raimundo Sousa

Universidade / University: Universidade Federal de Minas Gerais (UFMG)

Faculdade e Departamento / Unidade de Investigação - Faculty and Department /

Research Center: Faculdade de Letras, Departamento de Letras

Código Postal / Postcode: 31270-901

Cidade / City: Belo Horizonte

País / Country: Brasil

Email Institucional / Institutional email: raimundo_sousa@terra.com.br

Fonte: Medievalista [Em linha]. Direc. Bernardo Vasconcelos e Sousa. Lisboa: IEM.

Disponível em:

http://www2.fcsh.unl.pt/iem/medievalista/MEDIEVALISTA21/sousa2104.html

ISSN: 1646-740X

Data recepção do artigo / Received for publication: 21 de Janeiro de 2016

Data aceitação do artigo / Accepted in revised form: 5 de Setembro de 2016 


\section{Resumo}

Mediante análise de Topographia Hibernica, primeira descrição topográfica da Irlanda, empreendida pelo cronista medieval Giraldus Cambrensis, este ensaio investiga como o discurso colonial inglês procurou legitimar a colonização do território por meio da monstrificação dos habitantes nativos. Ao atribuir aos irlandeses, sob o signo da abjeção, toda sorte de anomalias de gênero com base nos repertórios de representação disponibilizados pela teratologia medieval, Cambrensis caracteriza a Irlanda como um celeiro de sexualidades monstruosas e, desse modo, procura naturalizar a colonização como um necessário processo civilizador.

Palavras-chave: Discurso colonial; Giraldus Cambrensis; Imaginação geográfica; Irlanda; Monstrificação.

\section{Abstract}

By analyzing Topographia Hibernica, first topographical description of Ireland, written by the medieval chronicler Giraldus Cambrensis, this paper investigates how the British colonial discourse sought to legitimize the colonization of the territory turning the native inhabitants into monsters. By assigning the Irish, under the sign of abjection, all sorts of gender anomalies based on the representation of repertoires offered by medieval Teratology, Cambrensis characterized Ireland as a hotbed of monstrous sexualities and thus tries to naturalize colonization as a necessary civilizing process.

Keywords: Colonial discourse; Giraldus Cambrensis; Geographical imagination; Ireland; Monstrification. 


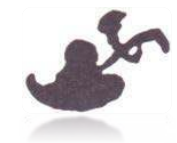

A monstrificação dos irlandeses na imaginação geográfica de Giraldus Cambrensis / Turning the Irish into monsters. The geographical imagination of Giraldus Cambrensis

Raimundo Sousa

\begin{abstract}
Monstra sane dicta perhibent a monstrando, quod aliquid significando, demonstrent; et ostenta ab obstendendo; et portenta a portendendo, id est praeostendendo; et prodigia, quod porro dicent, id est, futura praedicant.
\end{abstract}

Augustinus Hipponensis, De Civitate Dei

O atrelamento entre saber e poder, propalado por Francis Bacon e recodificado por Michel Foucault, exprime-se com propriedade em processos linguístico-discursivos como a representação - aqui compreendida, sob um prisma construcionista ${ }^{1}$, não como codificação especular de referentes apriorísticos, mas, isto sim, como um sistema

\footnotetext{
${ }^{1}$ Há, grosso modo, três abordagens concernentes à significação pela linguagem: a reflexiva, a intencional e a construcionista. A primeira pressupõe transparência entre signos e coisas, cabendo à linguagem atuar meramente como um "espelho" refletor do real. A segunda, por sua vez, reduz a representação às intenções do autor, tomando-o como detentor único de um significado restrito às suas pretensões de significação, e ignora a natureza interativa da linguagem, desconsiderando que a construção de sentidos depende de convenções linguísticas e códigos partilhados. Já a terceira, debitária do redimensionamento do conceito de linguagem pela virada linguística, reconhece o caráter coletivo dos processos linguísticos, assumindo que os significados são constituídos na e pela linguagem, e não confunde o mundo material com as práticas e os processos simbólicos por que esta opera nem nega a existência deste, pois os significados não são forjados pelo mundo material, mas, antes, pelos sistemas linguísticos atuantes como medium de interpretação, codificação e atribuição de sentidos a ele. Portanto, essa perspectiva considera que o sentido, em vez de intrínseco à materialidade do signo, é construído conforme a função simbólica que lhe é imputada; considera, ainda, que não se reflete o mundo ao representá-lo, mas de fato se o cria, uma vez que é precisamente a mediação dos sistemas de significação que o torna inteligível. HALL, Stuart - "The Work of Representation". in HALL, Stuart (ed.) - Representation: Cultural Representations and Signifying Practices. London: Sage, 2003, pp. 13-64.
} 
linguístico e cultural arbitrário e intrincado em relações de poder nas quais os significados são constituídos na e pela linguagem, os objetos a que estes remetem são forjados no ato mesmo de sua enunciação e as representações legitimadas estabelecem, embora nunca definitivamente, noções de identidade e diferença.

A operacionalidade das práticas representacionais na construção da realidade se evidencia na noção de espaço, que, conforme Lefebvre, constitui-se na relação tensional entre a materialidade e a imaginação, de modo que não se pode concebê-lo como dado apriorístico, mas, antes, como uma produção ${ }^{2}$. Em exemplo inequívoco de como o espaço constitui um construto cultural, o crítico literário inglês William Hazlitt, em ensaio de 1821 intitulado "Why distant objects please" ("Por que objetos distantes atraem"), assumia um construcionismo avant la lettre ao explicar a atratividade dos espaços remotos para o exercício da imaginação:

"Objetos distantes agradam porque, em primeiro lugar, implicam uma ideia de espaço e magnitude e porque, não estando muito próximos de nossos olhos, nós os vestimos com as cores indistintas e arejadas de fantasia. [...] Quando a paisagem desaparece da vista maçante, nós preenchemos o espaço estreito, sem visibilidade, com tons de desconhecido feitio, e tingimos a perspectiva nebulosa com esperanças, desejos e temores mais atraentes. [...] [T]udo quanto é colocado fora do alcance do sentido e do conhecimento, tudo o que é percebido de forma imperfeita, a fantasia acrescenta ao seu lazer"3.

Nessa prática de significação não raro inscrita em um sistema valorativo etnocêntrico e, portanto, calcada no enquadramento de alteridades etnogeográficas em determinados regimes de verdade que lhes atribuem significados frequentemente caros à instauração e / ou manutenção de assimetrias de poder -, o contato com uma cultura outra enseja um

\footnotetext{
${ }^{2}$ LEFEBVRE, Henri - La production de l'espace. Paris: Éditions Anthropos, 1974.

${ }^{3}$ HAZLITT, William - "Why distant objects please". in Table Talk. Vol. II. London: Henry Colburn and Co., 1822, pp. 219-238. No original: "Distant objects please, because, in the first place, they imply an idea of space and magnitude, and because, not being obtruded too close upon the eye, we clothe them with the indistinct and airy colours of fancy. [...] Where the landscape fades from the dull sight, we fill the thin, viewless space with shapes of unknown good, and tinge the hazy prospect with hopes and wishes and more charming fears. [...] [w] hatever is placed beyond the reach of sense and knowledge, whatever is imperfectly discerned, the fancy pieces out at its leisure". Tradução do autor.
} 
rito quase instantâneo, pautado na classificação desta, numa universalização narcísica de padrões evolutivos e códigos culturais, como sincrônica se análoga à nossa ou anacrônica se estranha a nossos paradigmas. Assim, a inscrição do Outro como parâmetro para a definição, simétrica ou contrastiva, de nossa própria identidade, sinaliza que, em última instância, os predicados que lhe atribuímos informam menos acerca dessa nossa exterioridade constitutiva ${ }^{4}$ do que de nós mesmos.

Em macroesfera, essa relação projetiva atingiu expressão máxima no imperialismo que, ao se valer de um exercício textual pautado na produção sistêmica de gêneros os mais diversos, conferiu respectivos estatutos de identidade e alteridade aos impérios e aos seus Outros, na medida em que a universalização de paradigmas culturais etnocêntricos chancelava polarizações supostamente ontológicas que, por sua vez, legitimavam a instauração e / ou manutenção de assimetrias de poder. Como, em um regime de representação etnologocêntrico, a possibilidade de (auto-)legitimação depende da prerrogativa de (d)(escre)ver, grupos despossuídos de autoridade discursiva para legitimar sua autoetnografia são inscritos / escritos por aqueles que, situados em posição favorável nas relações de poder, fazem-no em conformidade com acepções de cultura monocentrais cuja análise tem ocupado um veio dos estudos pós-coloniais atento aos modos como o Ocidente metropolitano tem forjado discursivamente sua alteridade desde a descoberta do "Novo Mundo" aos neocolonialismos contemporâneos 5 .

Todavia, em dissonância com a profusão de estudos acerca de processos de alterização transcontinentais, pouco se tem atentado para a invenção da alteridade no interior do território europeu, como se a Europa constituísse uma entidade homogênea, isenta de tensões internas. No contrafluxo dessa tendência, que contradiz a agenda dos estudos pós-coloniais pelo mesmo essencialismo ao qual esta se contrapõe, a atenção para

\footnotetext{
${ }^{4}$ Expressão tomada de empréstimo a Hall, para quem "é apenas mediante a relação com o Outro, a relação com o que não é, com precisamente o que falta, com o que se tem chamado de sua exterioridade constitutiva, que o sentido 'positivo' de qualquer termo - e, portanto, a sua 'identidade' - pode ser construído". HALL, Stuart - "Introduction: Who Needs Identity?". in HALL, Stuart; DU GAY, Paul (ed.) - Questions of Cultural Identity. London: Sage, 1996, pp. 1-17.

${ }^{5}$ Veja-se SAID, Edward - Orientalism: Western Conceptions of the Orient. New York: Pantheon Books, 1978; HULME, Peter - Colonial Encounters: Europe and the Native Caribbean. London: Methuen, 1986; PRATT, Mary Louise - Imperial Eyes: Travel Writing and Transculturation. London, New York: Routledge, 1992; MCCLINTOCK, Anne - Imperial Leather: race, gender and sexuality in the colonial contest. London: Routledge, 1995.
} 
relações de saber / poder em representações intracontinentais pode, ao explorar os limites conceituais desse campo intelectual, expandir suas fronteiras para além da centralidade na dicotomia Europa / "resto do mundo". Nessa perspectiva, o exame de como o discurso colonial inglês significou a Irlanda pode evidenciar como a produção de categorias raciais anterior ao século $\mathrm{XX}$ era mais complexa do que pressupõem alguns estudiosos do racismo, pois dependia menos da diferença cromática, anatomicamente inscrita, do que de relações de poder que a forjavam discursivamente; afinal, já que essa colônia situada na Europa mal possuía traços fenotípicos e particularidades geográficas (i.e. clima, fauna e flora "exóticos") que a distinguissem das nações "civilizadas", sua alterização dependia de estratégias discursivas ainda mais contundentes do que aquelas de que o império se valia para justificar, por exemplo, a colonização de regiões africanas, americanas e asiáticas.

Ao identificarem o racismo cultural como uma "nova" modalidade emergente na segunda metade do século XX, pautada no deslocamento do foco em distinções biológicas que fundamentavam o racismo científico para a ênfase em marcadores de diferenças culturais, estudiosos como Barker ${ }^{6}$ e Gilroy ${ }^{7}$ desconsideram que esse modus operandi supostamente mais sofisticado tem precedentes históricos muito anteriores. Haja vista a alterização da Irlanda pelo discurso colonial, processo que examinarei neste trabalho, ter-se assentado em disjunções de gênero pautadas na antinomia masculino / feminino - matriz estrutural para quaisquer outras distinções binárias em um sistema de significação falologocêntrico - a fim de estabelecer e naturalizar assimetrias de poder entre império e colônia.

De fato, longe de mera convenção terminológica, o emprego ontologizante e homogeneizante da categoria "Europa" por acadêmicos vinculados aos estudos póscoloniais contradiz sua agenda pelo elogio do mesmo essencialismo a que o campo intelectual se contrapõe e, portanto, pela não percepção de que o dualismo civilização / barbárie que sustentou a clivagem entre a "Europa" e sua exterioridade igualmente estabeleceu fronteiras intracontinentais. Na esteira de Said, que se refere ao Oriente

\footnotetext{
${ }^{6}$ BARKER, Martin - The New Racism: Conservatives and the ideology of the tribe. London: Junction Books, 1981.

${ }^{7}$ GILROY, Paul - There Ain't No Black in the Union Jack: The Cultural Politics of Race and Nation. Chicago: University of Chicago Press, 1987.
} 
como "um lugar onde se podia buscar experiência sexual inalcançável na Europa", gerações de estudiosos desconsideram que a racialização pela generização também se deu no interior do continente e que a Irlanda tanto figurava como uma paragem mais próxima na busca por gratificação erótica no circuito do desejo colonial quanto servia como "laboratório", enquanto primeira colônia inglesa, para testagem de estratégias que orientariam colonizações ulteriores.

Contudo, a especificidade geofísica da ilha, localizada adjuntamente à Inglaterra, impunha obstáculos à sua invenção como antítese desta última, obrigando o império a lançar mão de diferentes estratégias discursivas em consonância com repertórios de significação disponíveis em diferentes contextos históricos. Neste ensaio, parto do conceito de abjeção (do latim ab-jicere, expelir), tal como formulado por Kristeva ${ }^{9} \mathrm{e}$ redimensionado por McClintock ${ }^{10}$, para argumentar, a partir da leitura de Topographia Hibernica, tratado etnotopográfico da Irlanda empreendido pelo cronista medieval Giraldus Cambrensis, que o império, a fim de constituir uma identidade estável, precisava lançar fora tudo quanto ameaçasse sua unidade identitária. Assim, numa relação agonística em que se autolegitimava para definir a colônia em seus próprios termos, mas dependendo desta para sua própria definição, o império a inscrevia como um objeto de saber e, primordialmente, como um objeto abjeto que servia, enquanto o Outro, como repositório de tudo que o Eu (o império) negava em si mesmo. Graças a esse investimento projetivo, a Irlanda definiria o império via negativa enquanto sua nãoidentidade estruturante, de forma que o discurso colonial se fixaria, em sua invenção da colônia, na catalogação de tipos sociais abjetos que supostamente habitariam a Irlanda.

Repartida em diversos reinos, a Irlanda pré-colonial possuía um ordenamento administrativo descentralizado que a vulnerabilizava em face de recorrentes investiduras estrangeiras, tal como quando, no século XII, foi invadida pelos anglo-normandos em episódio histórico que abriria senda para a colonização inglesa. Em meados do século

\footnotetext{
${ }^{8}$ SAID, Edward - Orientalism..., p. 190.

${ }^{9}$ KRISTEVA, Julia - Powers of Horror: An Essay on Abjection. New York: Columbia University Press, 1982.

${ }^{10}$ MCCLINTOCK, Anne - Imperial Leather...
}

Medievalista online $N^{\circ} 21$ | Janeiro - Junho 2017 ( ) IEM - Instituto de Estudos Medievais 7 www2.fcsh.unl.pt/iem/medievalista 
XII, a rivalidade entre Dermot MacMurrough, rei de Leinster, e Tiernan O'Rourke, rei de Breifne, em disputas territoriais intestinas se acentuou quando o primeiro raptou a esposa do segundo. Deposto em 1167, Dermot se exilou na Inglaterra e, ao oferecer lealdade a Henry II, obteve suporte de cavaleiros normandos para recuperar seu território, mediante invasão ocorrida em 1169. Tal incursão abriu margem para que, pouco depois, o próprio Henry II invadisse a Irlanda e a anexasse ao reino anglonormando, mais tarde convertido no império inglês ${ }^{11}$.

Nos primórdios da colonização, o empecilho da proximidade entre metrópole e colônia era contornado por uma imaginação geográfica que instalava esta última numa espacialidade limítrofe entre o habitável e o inóspito, entre o domínio humano e o reino dos prodígios. Para tal, foi preponderante o exercício e alterização empreendido por Giraldus Cambrensis (1146-1223). Quando, em 1185, Príncipe John foi à Irlanda consolidar o jugo anglo-normando sobre o território, o cronista galês o acompanhou e, referendado pela experiência in loco, escreveu Topographia Hibernica (1187), texto fundador do discurso colonial na medida em que forneceu justifições imperialistas que seriam continuamente retomadas durante a era elisabetana ${ }^{12}$. Enviado como emissário real, Cambrensis prestou-se a uma minuciosa descrição da ilha numa obra que, informada pela organização cosmológica e representação concêntrica da imago mundi comum aos medievais, a localizava nas bordas mais extremas do ocidente e mesmo à parte do restante da terra, como se fosse "um outro mundo" 13 , inscrito no registro do maravilhoso. Afinal, para a cultura medieva, o maravilhoso - ou, nos termos da época, os mirabilia - tinha acepção distinta da que lhe atribuímos hodiernamente, pois não era um adjetivo sinônimo de admirável, mas uma ideia substantivada para designar um universo heteróclito à noção de normalidade. Ao "empurrar" a ilha para os confins do globo, sugerindo seu alheamento em relação ao mundo civilizado, o autor a tomava menos como um "texto" a ser decodificado do que como uma folha em branco, à mercê

\footnotetext{
${ }^{11}$ Veja-se COSGROVE, Art. (ed.) - A New History of Ireland: Volume II Medieval Ireland 1169-1534. Oxford: Clarendon Press, 1987; HARPER-BILL, Christopher; VAN HOUTS, Elisabeth (ed.) - A Companion to the Anglo-Norman World. Woodbridge: Boydell, 2003.

${ }^{12}$ Confira-se BRADSHAW, Brendan; HADFIELD, Andrew; MALLEY, Willy (ed.) - Representing Ireland: Literature and the Origins of Conflict 1534-1660. Cambridge: Cambridge University Press, 1993.

${ }^{13}$ CAMBRENSIS, Giraldus - Topographia Hibernica, et Expurgatio Hibernica. Ed. James F. Dimock. London: Longmans, Green, Reader, and Dyer, 1867, p. 23.
} 
da imaginação pré-imperial, e assim a caracterizava como um viveiro de subhumanidades monstruosas cujas anomalias se manifestariam, sobretudo, sexualmente.

Cambrensis não foi, a bem dizer, o primeiro a escrever sobre a Irlanda. Ainda no século primeiro d.C, o geógrafo grego Estrabão [Strabo] comentava em sua célebre

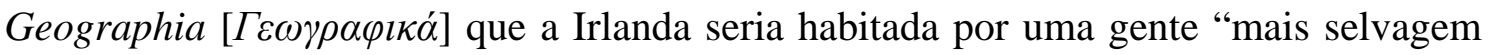
do que os bretões, alimentando-se de carne humana, (...) e considerando louvável devorar seus pais falecidos, bem como ter comércio abertamente (...) com suas próprias mães e irmãs"14. Todavia, a escolha de Topographia Hibernica como objeto de estudo se deve ao fato de que seu autor foi o primeiro estrangeiro a esboçar um perfil etnotopográfico da Irlanda após a conquista e, tendo em mira agradar ao rei, a quem dedicou o livro, representou a ilha com tamanha xenofobia que se tornaria referência para diversos agentes imperiais subsequentes ${ }^{15}$. Donde a relevância de examinar a obra de um agente pré-imperial, já que, embora a consolidação do império britânico - i.e., com consistente centralização estatal, disponibilidade de capital comercial, subsídio ideológico do protestantismo, povoamento sistemático do território expropriado e investimento expansionista - só ocorresse a partir do final do século XVI ${ }^{16}$, Cambrensis forneceu bases para a formação de estereótipos que sustentariam o imperialismo.

Os nativos, assim como descritos em Topographia Hibernica, mantinham tal imanência com a natureza que interagiam com a fauna local como se a ela pertencessem. Numa conjuntura em que a Igreja catalogava o bestialismo entre os pecados contra naturam, Cambrensis, que também era monge, identificava oportunamente sua voga entre os autóctones por meio de exemplos chocantes, tais como o "indigno e nefando ato" em que um bode copulava com uma mulher que o seduzira a fim de torná-lo "instrumento de gratificação para sua volúpia bestial" ${ }^{17}$. Tanto na análise jurídica, em que penalizava a mulher como culpada por abdicar de sua prerrogativa como ser racional e se submeter

\footnotetext{
${ }^{14}$ STRABO - The Geography of Strabo. Trad. H.C. Hamilton (vol. I a VI) e W. Falconer. Vol. I. London: Henry G. Bohn, 1854, pp. 298-299.

${ }^{15}$ MCVEIGH, Robbie; ROLSTON, Bill - "Civilising the Irish". Race \& Class v. 51, 1 (2009), pp. 2-28.

${ }^{16}$ Veja-se KENNY, Kevin - "The Irish in the Empire". in KENNY, Kevin (ed.) - Ireland and the British Empire. Oxford: Oxford University Press, 2004, pp. 90-122.

${ }^{17}$ CAMBRENSIS, Giraldus - Topographia Hibernica..., p. 110.
} 
a "tão torpe comércio com um animal bruto" ${ }^{18}$, quanto na exegese bíblica, em que se fundamentava nas prescrições do Levítico para sugerir que ambos deveriam ser igualmente exterminados, Cambrensis se empenhava em ressaltar não só a animalidade da mulher irlandesa, mas também sua condição de mais ínfima do que as próprias bestas.

Decerto com vistas a agradar ao Rei, que lhe confiara a escritura (em sentido textual) da terra devassada como escritura (em sentido legal) simbólica de sua propriedade, o cronista procurava deslegitimar a autoridade dos reis locais e sua ascensão ao poder pela monstrificação da cerimônia de posse como um rito bestial que, como sugere o relato seguinte, incluía fornicação entre o ascendente ao trono e uma mula:

"Estando todas as pessoas daquela terra [Ulster] reunidas em um lugar, uma mula branca é levada para o meio delas, e aquele que está para ser empossado não como um príncipe, mas como um bruto, não como um rei, mas como um criminoso, vem para diante das pessoas de quatro, mostrando-se uma besta com não menos impudência do que imprudência. Após a mula ser imediatamente sacrificada, picada em pedaços e cozida, um banho é preparado para ele daquele caldo. Sentado ali, ele come a carne que lhe é trazida, e as pessoas se postam em volta e partilham dela também. Ele então deve beber do caldo no qual é banhado, não o tirando com nenhum recipiente, nem mesmo com a mão, mas o lambendo com a boca. Tendo esses rituais sido cumpridos ilicitamente, sua autoridade real e seu poderio são ratificados"19.

Cambrensis não apenas se dedicava à descrição de práticas de bestialismo como fazia questão de relacioná-las, em efeito de causalidade, com a profusão de seres monstruosos

\footnotetext{
${ }^{18}$ CAMBRENSIS, Giraldus - Topographia Hibernica..., p. 169.

${ }^{19}$ CAMBRENSIS, Giraldus - Topographia Hibernica..., p. 169. No original: "Collecto in unum universo terrae [Ulster] illius populo, in medium producitur jumentum candidum. Ad quod sublimandus ille non in principem sed in beluam, non in regem sed exlegem, coram omnibus bestialiter accedens, non minus impudenter quam imprudenter se quoque bestiam profitetur. Et statim jumento interfecto, et frustatim in aqua decocto, in eadem aqua balneum ei paratur. Cui insidens, de carnibus illis sibi allatis, circumstante populo suo et convescente, comedit ipse. De jure quoque quo lavatur, non vase aliquo, non manu, sed ore tantum circumquaque liaurit et bibit. Quibus ita rite, non recte completis, regnum illius et dominium est confirmatum". Tradução do autor.
} 
que habitariam a ilha. A afeição dos hibérnicos pelo coito antinatural explicaria a existência de criaturas como um "homem-bezerro", nascido nas montanhas de Glendalough "em virtude do comércio entre um homem e uma vaca" 20 . Havia ainda um "homem-boi", assim descrito:

"Ele tinha um corpo inteiramente humano, à exceção das extremidades, que eram de um boi. Das juntas a partir das quais as mãos normalmente se estenderiam dos braços e os pés das canelas, ele exibia os cascos de um boi. Sua cabeça era totalmente careca, desfigurada pela calvície tanto atrás quanto na frente, com apenas manchas pintadas aqui e acolá em vez de fios de cabelos. Seus olhos eram enormes e bovinos, muito em razão tanto de sua rotundidade quanto de sua coloração. Ele tinha um rosto plano, sem protuberância nenhuma senão duas narinas abertas no lugar de um nariz; ele não falava; em vez disso, apenas emitia um som alto e berrante" 21 .

Paradoxalmente, o homem-animal estava, a um só tempo, aquém e além do humano, pois, de um lado, padecia de carências que o rebaixavam da humanidade e, de outro, transcendia os limites da corporeidade humana. Conforme Agamben, a máquina antropológica moderna emergiu quando se definia o homem pela ruptura entre o humano e o animal, tornando imperioso erradicar daquele tudo quanto remetesse à animalidade $^{22}$. Todavia, para o imaginário medieval o alheio ao homem não derivava propriamente de seu componente animal, de sorte que os monstros não eram definidos pelo binarismo humanidade / animalidade. Donde a recorrência, em Topographia Hibernica, de monstros híbridos que amalgamam o homem e o animal com implicação não de contraste, mas de complementaridade entre as duas partes. De fato, em sua liminaridade ontológica, monstros desconjuntados como esse "homem-boi” sugeriam um desmantelamento da polaridade natureza / cultura, cara aos medievais, e, alocados

\footnotetext{
${ }^{20}$ CAMBRENSIS, Giraldus - Topographia Hibernica..., p. 108.

${ }^{21}$ CAMBRENSIS, Giraldus - Topographia Hibernica..., p. 108. No original: "Habebat enim totum corpus humanum praeter extremitates, quae bovinae fuerant. A juncturis namque quibus et manus a brachiis, et pedes a tibiis porriguntur, ungulas bovis expressas praeferebat. Caput ei sine crine totum; tam in occipite, quam anteriori parte, calvitio deforme; raras tantum lanugines per loca pro capillis habens. Oculi grossi; tam rotunditate quam colore bovini. Facies oretenus subinde plana; pro naso, praeter duo narium foramina, nullam eminentiam habens. Verba ei nulla. Mugitum enim tantum pro sermone reddebat". Tradução do autor.

${ }^{22}$ AGAMBEN, Giorgio - L'aperto. L'uomo e l'animale. Torino: Bollati Boringhieri, 2002.
} 
num espaço intersticial entre categorias antitéticas, figuravam como tropologias para a especificidade dos irlandeses, cuja hibridação entre o animal e o humano exprimia a incompletude de sua transição do estado de natureza para o de cultura.

Também habitariam a ilha criaturas sexualmente híbridas, cujo hermafroditismo reforçava o suposto desalinho de uma terra caótica em relação à harmonia cósmica. Enquanto os homens-bestas transcendiam a distinção entre humanidade e animalidade, os(as) hermafroditas, em sua bipolaridade sexual estruturante, extrapolavam a estratificação de gênero, deslocando o binarismo homem / mulher. Haja vista uma criatura que "comungava da natureza de ambos os sexos e era hermafrodita", pois "[d]o lado direito do rosto tinha uma barba longa e densa [...], como um homem; e do lado esquerdo os lábios e o queixo eram lisos e sem pêlos, como uma mulher" ${ }^{23}$. Seres híbridos, inscritos na liminaridade entre o humano e o animal, entre o masculino e o feminino, os monstros irlandeses não passavam de figuras tropológicas para metonimizar o desalinho da Irlanda com a civilização e, assim, justificar a cristianização mais ortodoxa e a política expropriatória inglesa. A ambiguidade de gênero, decorrente da inapreensividade em categorias estanques, inscrevia o(a) hermafrodita nos interstícios do regime classificatório e assim exemplificava, pela metonímia da desordem de gênero, o caos social em que a ilha supostamente se encontrava.

Contudo, essa invenção da alteridade pela monstrificação deixa entrever a fragilidade dos próprios aparatos de representação protoimperialistas. Com efeito, o monstro, categorialmente inapreensível, ratifica a inconsistência de nossos regimes classificatórios e, por conseguinte, impõe desafio aos sistemas hierárquicos binários ${ }^{24}$. Esses entes inclassificáveis são sintomáticos da incapacidade dos sistemas de classificação existentes acomodarem a complexa heterogeneidade dos seres. Afinal, tais sistemas se pautam no princípio da similitude, já que, segundo Foucault, "a história da ordem das coisas seria a história do Mesmo - daquilo que, para uma cultura, é, simultaneamente, disperso e aparentado, a ser distinguido por marcas e recolhido em

\footnotetext{
${ }^{23}$ CAMBRENSIS, Giraldus - Topographia Hibernica..., p. 107.

24 Confira-se COHEN, Jeffrey - Monster Theory: Reading Culture. Minneapolis: University of Minnesota Press, 1996; WILlIAMS, David - Deformed Discourse: The Function of the Monster in Medieval Thought and Literature. Exeter: University Exeter Press, 1996.
} 
identidades" ${ }^{25}$. Se a sustentabilidade da taxonomia não prescinde do princípio da menor diferença possível entre as coisas, é precisamente graças ao que extrapola as leis taxonômicas que os sistemas de classificação passam por contínuos processos de reformulação reveladores de sua precariedade. Não é por outra razão que, segundo Kappler,
"Procurar o monstro é uma caça fértil e imprevisível: o monstro tende a escapar constantemente, o que é uma das atrações dessa busca sem fim; é melhor dedicar-se a ele com flexibilidade, prazer e até mesmo imaginação do que persistir cegamente em uma "lógica" inadequada; é melhor fazer uma arte do que um duelo, que seria conquistado por antecipação por esse adversário protéico" 26 .

Como toda sociedade estabelece cânones (est)éticos informados por sua cosmovisão, no Medievo tais cânones eram balizados pelo cristianismo, assentado na concepção do homem como criação da arquitetura divina. Assim, "[o] cristão, para quem o homem é feito à imagem de Deus, tem por monstro todo indivíduo que se desvia muito representação que geralmente se faz da divindade" 27 . Cambrensis, ao relatar nunca ter visto noutra nação tantos indivíduos "com algum defeito natural" e creditar tais malformações ao castigo divino frente à sordidez dos modos e costumes locais ${ }^{28}$, certamente se pautava em Agostinho de Hipona [Augustinus Hipponensis], cuja influente reflexão acerca do estatuto dos monstros partia da premissa de que Deus não seria capaz de criar seres imperfeitos senão como advertência aos homens - donde seu atrelamento, na epígrafe deste ensaio, do termo monstro aos verbos mostrar e

25 FOUCAULT, Michel - Les mots et les choses: une archeologie des sciences humaines. Paris: Gallimard, 1966, p. 15. No original: "l'histoire de l'ordre des choses serait l'histoire du Même, - de ce qui pour une culture est à la fois dispersé et apparenté, donc à distinguer par des marques et à recueillir dans des identités". Tradução do autor.

${ }^{26}$ KAPPLER, Claude - Monstres, démons et merveilles à la fin du Moyen Age. Paris: Payot, 1980, p. 14. No original: "Chercher le monstre est une chasse fertile et imprévus: le monstre, constamment, tend à s'échapper et c'est là l'un des charmes de cette poursuite sans fin; mieux vaut s'y adonner avec souplesse, avec plaisir et même avec fantasie, que s'obstiner aveuglément dans une 'logique' inadéquate; mieux vaut en faire un art qu'un duel, lequel serait gagné d'avance par cet adversaire protéiforme". Tradução do autor.

27 LECOUTEUX, Claude - Les monstres dans la pensée médiévale européenne. Paris: Presses de l'Université de Paris-Sorbonne, 1993, p. 11. No original: "Le chrétien pour qui l'homme est fait à l'image de Dieu, tient pour un monstre tout individu qui s'écarte par trop de la représentation qu'on se fait habituellement de la divinité". Tradução do autor.

${ }^{28}$ CAMBRENSIS, Giraldus - Topographia Hibernica..., p. 181. 
demonstrar $^{29}$. Numa conjuntura em que a incapacidade do discurso médico explicar devidamente a incidência de portadores de anomalias provocadas por falhas ou alterações genéticas os relegava à condição de monstros, aquele que hoje se enquadraria no tipo sociológico do outsider ou marginal figurava, no imaginário medieval, como ser monstruoso que poderia ser inventariado, dentro do bestiário, ao lado de lobisomens, ciclopes e gigantes ${ }^{30}$. Assim, a concepção agostiniana sobre a monstruosidade foi predominante na hermenêutica do monstruoso até o século $\mathrm{XIII}^{31}$. Se, para essa teratologia medieval, os monstros deveriam ser interpretados pela "mensagem" que corporificavam, Cambrensis encontrou nessas figuras um dispositivo retórico crucial para a alterização dos irlandeses ao investi-las didaticamente como sinais enviados por Deus para lhes "mostrar" sua reprovação em face de seus maus costumes. Portanto, essa horda de homens-bestas e hermafroditas, resultantes de práticas sexuais antipáticas às leis naturais e aos desígnios divinos, não apenas inscrevia a Irlanda como o avesso dos códigos de perfeição físico-moral como, consequentemente, assinalava o imperativo da intercessão civilizadora.

A ênfase na dissonância entre a natureza opulenta da ilha, descrita como um "repositório especial" da natureza, que ali estocava "seus mais notáveis e preciosos tesouros" ${ }^{32}$, e os autóctones desqualificados para merecê-la, já que, entregues aos mais torpes vícios, não usufruíam devidamente das riquezas de que dispunham, constitui o nevrálgico da monstrificação da sexualidade irlandesa em Topographia Hibernica: a justificação da premência de uma intervenção empreendedora para atender ao clamor da natureza pela sua devida exploração. Ao interpretar como barbárie a disjunção hibérnica em face do paradigma extrativista e mercantil que se desenhava na metrópole e ao denunciar a indolência dos irlandeses como insuflada pela depravação sexual, o cronista assumia o processo civilizador inglês como lei universal para condenar o modus vivendi nativo como signo de sua estagnação desenvolvimental. Assim, prenunciando a clivagem entre erotismo e trabalho em que o capitalismo se fundaria ${ }^{33}$, denunciava que

\footnotetext{
${ }^{29}$ AUGUSTINUS - De Civitate Dei. Venetiis: N. Jensen, 1475.

${ }^{30}$ LECOUTEUX, Claude - Les monstres...

${ }^{31}$ WILLIAMS, David - Deformed Discourse...

${ }^{32}$ CAMBRENSIS, Giraldus - Topographia Hibernica..., p. 23.

33 Veja-se MARCUSE, Herbert - Eros und Kultur: Ein philosophischer Beitrag zu Sigmund Freud. Stuttgart: Klett, 1957.
} 
enquanto a civilização rumava para um progresso material que demandava exploração otimizada de matérias-primas, a Irlanda seguia uma ordem inversa, na qual a prodigalidade de monstros ali engendrados seria a expressão mais inequívoca de seu abandono à impudicícia.

Informados pelo clericalismo, os estereótipos imputados aos irlandeses eram balizados, não raro, por um sistema de representação bipolar que cindia Carne e Espírito, Bem e Mal, Deus e Satã. Assim como Deus e Diabo, entidades interdependentes, adquirem significado tão-somente pela relação oposicional entre si, também a Inglaterra precisava ter como contrapartida uma Irlanda demoníaca para se legitimar cristã e, desse modo, justificar o imperativo da intervenção cristianizadora. Contudo, uma vez que, diferentemente dos ameríndios e africanos, os irlandeses se haviam cristianizado $a$ priori da conquista, a missão evangelizadora como justificativa do intervencionismo seria inviável se não chancelada pela comprovação de que o Diabo não fora eficazmente expulso da ilha. E tal comprovação se daria, sobretudo, pela demonização da sexualidade nativa.

Quando do encontro colonial, o catolicismo irlandês, longe de apartado das práticas sociais mundanas, encontrava-se embebido em um caldo cultural balizado pela interpenetração de legados os mais diversos. Entretanto, os agentes imperiais, inscritos numa ordem do discurso intolerante ao sincretismo, exconjuravam suas liturgias como rituais tão macabros quanto libertinos. Em um dos exemplos mais pungentes de demonização do cristianismo heterodoxo dos irlandeses pelo discurso colonial, Cambrensis assim descreve um rito iniciático que seria praticado em igrejas locais:

"Quando desejam filiar alguém, eles se arregimentam, em sua companhia, em algum lugar sagrado, sob o pretexto de congregação religiosa e pacífica. Primeiramente, eles seguem em procissão ao redor da igreja; depois, adentrando-a, reúnem-se numa aliança indissolúvel defronte ao altar, com juramentos prodigamente multiplicados sobre as relíquias dos santos e confirmados pela celebração da missa e pelas orações dos santos sacerdotes, tal como se fosse uma aliança solene. Finalmente, como ratificação ainda mais forte de sua liga [...], eles bebem o sangue uns dos outros, que é 
derramado com esse propósito. [...] Quantas vezes, no próprio ato de tal aliança sendo feita por homens sangrentos e enganosos, tanto sangue tenha sido derramado fraudulenta e iniquamente, que um ou outro tenha desmaiado no local! Quantas vezes o mesmo instante que testemunhou o contrato, ou que se lhe seguiu, viu-o ser quebrado de maneira inédita por um divórcio sangrento!"34.

Como sugere a passagem, a feição diabólica da firmação da "aliança" defronte ao altar residia em sua carnavalização da missa tradicional numa apropriação disruptiva que dessacralizava o rito solene, investindo-o de significação profana e, mais ainda, trazia à tona a natureza canibalística da própria missa na qual o sangue de Cristo é consumido simbolicamente. O relato insinua, ainda, a presença do homoerotismo como catalizador da cerimônia ao acentuar a conotação marital da união sacramentada pela degustação coletiva do sangue de outrem numa carnavalização da Sagrada Eucaristia mediante o rito homoerótico balizado pela troca de fluidos corporais.

A fabricação do monstro se assenta, basilarmente, na deformação por implicar conjunção disjuntiva mediante amalgamação de partes incongruentes. Williams observa que, para Isidoro de Sevilha, um dos primeiros a versar sobre o tema, o ser monstruoso se constitui por meio dos seguintes processos:

“(1) hipertrofia do corpo, (2) atrofia do corpo, (3) excrescência de partes corporais, (4) superfluidade de partes corporais, (5) privação de peças, (6) mistura de partes do corpo humano e de animais, (7) nascimentos de animais por mulheres humanas, (8) má localização de órgãos ou partes do

\footnotetext{
${ }^{34}$ CAMBRENSIS, Giraldus - Topographia Hibernica..., p. 167. No original: "Sub religionis et pacis obtentu ad sacrum aliquem locum conveniunt, cum eo quem oppetere cupiunt. Primo compaternitatis foedera jungunt: deinde ter circa ecclesiam se invicem portant: postmodum ecclesiam intrantes, coram altari reliquiis sanctorum appositis, sacramentis multifarie praestitis, demum missae celebratione, et orationibus sacerdotum, tanquam desponsatione quadam indissolubiliter foederantur. Ad ultimum vero, ad majorem amicitiae confirmationem, [...] sanguinem sponte ad hoc fusum uterque alterius bibit [...]. $O$ quoties in ipso desponsationis hujus articulo, a viris sanguinum et dolosis tam dolose et inique funditur sanguis, ut alteruter penitus maneat exsanguis! O quoties eadem hora et incontinenti vel sequitur vel praevenit, vel etiam inaudito more sanguinolentum divortium ipsam interrumpit desponsationem!". Tradução do autor.
} 
corpo (9), crescimento disparatado (nascer velho), (10) seres compostos, (11) hermafroditas, (12) raças monstruosas" 35 .

Conforme exposto neste ensaio, a Irlanda, tal como monstrificada por Cambrensis, constituía um viveiro de seres monstruosos cuja deformação obedecia a vários dos critérios supracitados. Como dispositivo representacional vinculado ao discurso protoimperialista, a monstrificação figurou como forma de inscrever a Irlanda como alteridade absoluta do que séculos mais tarde se constituiria como império inglês. Assim como no imaginário ocidental o homem ${ }^{36}$ foi designado apolíneo e racional, em oposição à mulher, supostamente dionisíaca e instintiva, o império inglês se definiu pela mesma dicotomia em relação à colônia irlandesa, na medida em que, assentado numa equação dualista que codificava a (cons)ciência como masculina e do objeto de saber como feminino, dependeu largamente de estratificações de gênero para referendar medidas intervencionistas e exploratórias.

Uma vez que o corpo monstruoso incita, em seu caos formal, não apenas o olhar como, sobretudo, o olhar a partir de uma mirada ordenadora, a invenção da Irlanda como um reduto de sexualidades monstruosas dava caução ao projeto protoimperialista na medida em que a intervenção inglesa teria como justificativa a "humanização" dos hábitos locais. Por isso os monstros irlandeses, na qualidade de abjetos, isto é, expelidos, não são mais do que pólos invertidos do ordenamento social idealizado pelo império, que, ávido por ratificar sua identidade cultural civilizada, procurava contrastivamente na colônia e em seus habitantes uma imagem estável de si mesmo. Se considerarmos que o monstro, enquanto projeção imaginária de temores e ansiedades, corporifica tudo quanto é recalcado pela cultura dominante ou relegado ao domínio da abjeção e por isso emerge

\footnotetext{
${ }^{35}$ WILLIAMS, David - Deformed Discourse..., p. 107. No original: "(1) hypertrophy of the body, (2) atrophy of the body, (3) excrescence of bodily parts, (4) superfluity of bodily parts, (5) deprivation of parts, (6) mixture of human and animal parts, (7) animal births by human women, (8) mislocation of organs or parts in the body, (9) disturbed growth (being born old), (10) composite beings, (11) hermaphrodites, (12) monstrous races". Tradução do autor.

${ }^{36}$ Por "homem" me refiro a um paradigma ocidental de masculinidade hegemônica, alicerçado na filosofia grega e no projeto iluminista, que não necessariamente engloba todos os sujeitos sociais do gênero masculino.
} 
em conjunturas de crise como um terceiro termo que problematiza polaridades ${ }^{37}$, os corpos monstruosos dos irlandeses também constituem vestígios das estruturas imaginárias com que se atribuía sentido ao desconhecido e ao amedrontador.

\section{Referências bibliográficas:}

\section{Fontes}

AUGUSTINUS - De Civitate Dei. Venetiis: N. Jensen, 1475.

CAMBRENSIS, Giraldus - Topographia Hibernica, et Expurgatio Hibernica. Ed. James F. Dimock. London: Longmans, Green, Reader, and Dyer, 1867.

HAZLITT, William - "Why distant objects please". in Table Talk. Vol. II. London: Henry Colburn and Co., 1822, pp. 219-238.

STRABO - The Geography of Strabo. Trad. H.C. Hamilton (vol. I a VI) e W. Falconer. Vol. I. London: Henry G. Bohn, 1854.

\section{Estudos}

AGAMBEN, Giorgio - L'aperto. L'uomo e l'animale. Torino: Bollati Boringhieri, 2002.

BARKER, Martin - The New Racism: Conservatives and the ideology of the tribe. London: Junction Books, 1981.

BENSHOFF, Harry - Monsters in the Closet: Homosexuality and the Horror Film. New York: Manchester University Press, 1997.

BERNHEIMER, Richard - Wild Men in the Middle Ages. Cambridge: Harvard University Press, 1952.

\footnotetext{
${ }^{37}$ Veja-se BERNHEIMER, Richard - Wild Men in the Middle Ages. Cambridge: Harvard University Press, 1952; COHEN, Jeffrey - Monster Theory...; BENSHOFF, Harry - Monsters in the Closet: Homosexuality and the Horror Film. New York: Manchester University Press, 1997.
} 
BRADSHAW, Brendan; HADFIELD, Andrew; MALLEY, Willy (ed.) - Representing Ireland: Literature and the Origins of Conflict 1534-1660. Cambridge: Cambridge University Press, 1993.

CIXOUS, Helene - "Sorties: Out and Out: Attacks/Ways Out/Forays". in CIXOUS, Helene; CLEMENT, Catherine - The Newly Born Woman. Minneapolis: University of Minnesota Press, 1986, pp. 63-132.

COHEN, Jeffrey - Monster Theory: Reading Culture. Minneapolis: University of Minnesota Press, 1996.

COSGROVE, Art. (ed.) - A New History of Ireland: Volume II Medieval Ireland 11691534. Oxford: Clarendon Press, 1987.

FOUCAULT, Michel - Les mots et les choses: une archeologie des sciences humaines. Paris: Gallimard, 1966.

GILROY, Paul - There Ain't No Black in the Union Jack: The Cultural Politics of Race and Nation. Chicago: University of Chicago Press, 1987.

HALL, Stuart - "Introduction: Who Needs Identity?". in HALL, Stuart; DU GAY, Paul (ed.) - Questions of Cultural Identity. London: Sage, 1996, pp. 1-17.

HALL, Stuart - "The Work of Representation". in: HALL, Stuart (ed.) Representation: Cultural Representations and Signifying Practices. London: Sage, 2003, pp. 13-64.

HARPER-BILL, Christopher; VAN HOUTS, Elisabeth (ed.) - A Companion to the Anglo-Norman World. Woodbridge: Boydell, 2003.

HULME, Peter - Colonial Encounters: Europe and the Native Caribbean. London: Methuen, 1986. 
KAPPLER, Claude - Monstres, démons et merveilles à la fin du Moyen Age. Paris: Payot, 1980.

KENNY, Kevin - "The Irish in the Empire". in KENNY, Kevin (ed.) - Ireland and the British Empire. Oxford: Oxford University Press, 2004, pp. 90-122.

KRISTEVA, Julia - Powers of Horror: An Essay on Abjection. New York: Columbia University Press, 1982.

LECOUTEUX, Claude - Les monstres dans la pensée médiévale européenne. Paris: Presses de l'Université de Paris-Sorbonne, 1993.

LEFEBVRE, Henri - La production de l'espace. Paris: Éditions Anthropos, 1974.

MARCUSE, Herbert - Eros und Kultur: Ein philosophischer Beitrag zu Sigmund Freud. Stuttgart: Klett, 1957.

MCCLINTOCK, Anne - Imperial Leather: race, gender and sexuality in the colonial contest. London: Routledge, 1995.

MCVEIGH, Robbie; ROLSTON, Bill - "Civilising the Irish". in Race \& Class v. 51, 1 (2009), pp. 2-28.

PRATT, Mary Louise - Imperial Eyes: Travel Writing and Transculturation. London, New York: Routledge, 1992.

SAID, Edward - Orientalism: Western Conceptions of the Orient. New York: Pantheon Books, 1978.

WILLIAMS, David - Deformed Discourse: The Function of the Monster in Medieval Thought and Literature. Exeter: University Exeter Press, 1996. 


\section{COMO CITAR ESTE ARTIGO}

\section{Referência electrónica:}

SOUSA, Raimundo - “A monstrificação dos irlandeses na imaginação geográfica de Giraldus Cambrensis". Medievalista 21 (Janeiro-Junho 2017). [Em linha] [Consultado dd.mm.aaaa]. Disponível em

http://www2.fcsh.unl.pt/iem/medievalista/MEDIEVALISTA21/sousa2104.html ISSN 1646-740X.

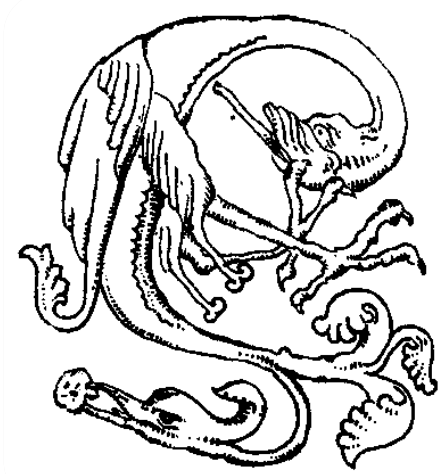

